\title{
The Correlation Between Desire Thinking and Compulsive Buying
}

\author{
Gisele Liu ${ }^{1, *}$ \\ ${ }^{1}$ The Bishop Strachan School, Toronto, Ontario, M4V 1N5, Canada \\ *Corresponding author.Email: liugisele@gmail.com
}

\begin{abstract}
In today's developed society, purchasing is made easier than ever before with new technology and online stores, causing products to be more accessible to shoppers who spend excessively without control. Through a proposed experiment, this study investigates the effectiveness of desire thinking, a voluntary cognitive process, in preventing this problematic behaviour - compulsive buying. The experiment recruits a total sample of 300 shoppers from the general population who have shopped consistently in the past few years and are 18 years of age or older. Results from self-reported questionnaires demonstrate the correlation between desire thinking and participants suffering from compulsive buying disorder compared to the correlation between desire thinking and participants without compulsive buying disorder. The expected results indicate that higher levels of desire thinking positively correlate with compulsive buying. This is because desire thinking would only cause an increased amount of craving and negative affect long-term since the desired target of shopping is perseveratively elaborated upon and not achieved. Therefore, because desire thinking can be used to increase shopping tendencies in those suffering from compulsive buying, this paper analyzes how desire thinking can be utilized by marketers and retailers to increase craving and encourage those affected by compulsive buying to continue compulsively purchasing products.
\end{abstract}

Keywords: Desire thinking, compulsive buying, verbal perseveration, imaginal prefiguration, correlational study, shopping

\section{INTRODUCTION}

The present-day conceptualization of addictive behavior can no longer only be defined by traditionally common substance-related addictions such as alcohol, smoking, and the consumption of illegal drugs. Troublesome behavior such as excessive shopping now also displays the same common set of underlying biopsychosocial addictive mechanisms, some of which are preoccupation, compulsiveness and loss of control [1]. With progressing digitalization that makes it easier to access stores, it is now being argued that excessive shopping is more prevalent than ever among a large sample of adolescents. One risk factor for this consumer behavior would be desire thinking. However, past research has only investigated the association between desire thinking and more traditional substance-related addictive behaviors. The complex interrelationships between desire thinking and compulsive buying remain understudied, creating a chasm that impedes a coherent understanding of the drivers of growing shopping addictions and the potential collateral damage this addiction may cause. This study bridges this gap in research by investigating how and why desire thinking can be a risk factor for compulsive buying long-term.

\section{THEORETICAL BACKGROUND}

Desire thinking, also known as DT, is a voluntary cognitive process entailing the elaboration of a desired target at a verbal and imaginal level [2]. Therefore, it consists of two components: Imaginal Prefiguration and Verbal Perseveration. More specifically, Imaginal Prefiguration involves the inclination to prefigure images about desire-related content and experience while verbal perseveration refers to the perseveration of verbal thoughts about desire-related content and experience [3]. Perseverative thinking styles such as rumination and worry differ from Desire thinking because Desire Thinking is characterized by positive target-related experiences and self-motivational statements [3].

Compulsive buying disorder, also known as shopping addiction, can harmfully affect an individual and their 
social and occupational life. McElroy et al 's (1994) preliminary operational diagnostic criteria describe compulsive buying as problematic buying behavior that is uncontrollable, markedly distressing, time-consuming, and/or resulting in family, vocational, and/or financial difficulties. Compulsive buyers experience various moods of satisfaction in the process of purchasing and develop thoughts, urges and preoccupations that prepare them for shopping and spending [4]. This occurs even when they recognize that their behavior is clearly having a negative impact on their life. Many people develop compulsive buying disorder due to gratification, idea shopping, adventure, and other various hedonic shopping motivations [5]. Compulsive buying disorder appears to be confined to high-income countries such as Brazil, England, France, Germany and the USA, although it is found throughout the world. The age at which compulsive buying starts has been reported to range from 18 to 30 years [4]. Whether compulsive buying is classified as a serious mental illness has been controversial and heavily debated as it could be regarded as the 'medicalizing' of a 'moral' problem. Other nonchemical dependencies, such as internet addiction, gambling and work addiction, are being similarly disputed. In today's developed society, with more and more ways to easily access products through online stores such as Amazon, shopping is made more enticing than ever before. Therefore, it is important to investigate the factors contributing to people's decision to consume and spend irrationally.

\section{METHOD}

\subsection{Participants}

A total sample of 300 shoppers (150 female, 150 male) are recruited from the general population. For purposes of inclusion in this study, participants are required to do or have done the following things: shopped consistently in the past few years; be 18 years of age or above; consent to participate in the study; understand spoken and written English.

Participants will be divided into two subgroups: those affected with a shopping addiction and those who are not. The criterion for inclusion in the subgroups will be determined by the score attained on The Bergen Shopping Addiction Scale (BSAS). Participants who score 3 (agree) or 4 (completely agree) on at least four of the seven items are classified as shopping addicts. Final scores in the 0-3 range are not indicative of shopping addiction [6].

\subsection{Self-Report Instruments}

Bergen Shopping Addiction Scale (BSAS). The BSAS is a brief screening tool for assessing the severity of shopping addiction. It contains a small number of items that reflect the seven elements of addiction (salience, mood modification, conflict, tolerance, withdrawal, relapse, and problems), thus ensuring its content validity in an addiction framework [6]. Four items for each addiction criterion were constructed based upon a general literature review of common symptoms associated with shopping and buying addiction. The response options were: completely disagree (0), disagree (1), neither disagree nor agree (2), agree (3) and completely agree (4) [6]. Higher scores indicate higher levels of shopping addiction. The top items related to each addiction criterion are retained in the final scale [6].

Desire Thinking Questionnaire (DTQ). The DTQ consists of two factors, each including 5 items. The first factor involves the perseveration of verbal thoughts about desire-related content and experience (verbal perseveration) and includes items which ask participants the degree of truth in tendencies such as "I mentally repeat to myself that I need to practice the desired activity" [3]. The second factor entails the tendency to prefigure images about desire-related content and experiences (imaginal prefiguration) and includes items such as "I imagine myself doing the desired activity" [3]. Items are general in content and refer to the desired activity that is specified in the instructions. Higher scores represent higher levels of desire thinking. The DTQ total score and factor scores show good factor structure, internal consistency, and test-retest reliability [3].

\subsection{Procedure}

The first page of the virtual study given to participants will explain the purpose of the study: "To investigate the relationship between compulsive buying and desire thinking." Participants will then be directed, if consenting to participate in the study, to a second page consisting of basic demographic questions and the selfreport instruments. Once both are completed, participants will be informed that they should click on the "Submit" button. Once participants have clicked on "Submit", their data will be collected anonymously. All participants will then be debriefed.

Results would demonstrate the relationship between desire thinking and those with a shopping addiction compared to the relationship between desire thinking and those without a shopping addiction. This would allow us to see whether desire thinking could be a risk factor for compulsive buying. 


\section{DATA}

Table 1. Data of the DTQ results of internet users

\begin{tabular}{|c|c|c|}
\hline & $\begin{array}{c}\text { Problematic Internet } \\
\text { Users }\end{array}$ & $\begin{array}{c}\text { Nonproblematic Internet } \\
\text { Users }\end{array}$ \\
\hline Weekly Internet Use in Hours & 24.0 & 9.8 \\
\hline $\begin{array}{c}\text { Desire Thinking } \\
\text { Questionnaire_Verbal } \\
\text { Perseveration }\end{array}$ & 7.8 & 5.6 \\
\hline $\begin{array}{c}\text { Desire Thinking } \\
\text { Duestionnaire_Imaginal } \\
\text { Prefiguration }\end{array}$ & 7.5 & 5.6 \\
\hline
\end{tabular}

In a similar study conducted to see whether desire thinking could be a predictor/risk factor for internet overuse in young people, 250 Internet users were recruited from the general population to be used as participants in the study. They each took an internet addiction test that split them up between problematic and non-problematic internet users [2]. Problematic internet users on average used the internet for about 24 hours or more in total per week, while non-problematic internet users used the internet for about 9.8 hours or less in total [2]. Both groups were given the DTQ. Data results showed that levels of desire thinking were significantly higher in problematic internet users than in nonproblematic internet users, proving that both verbal perseveration and imaginal prefiguration predicted problematic internet use. This essentially means that practicing desire thinking could lead to and be a reason for addictive internet use rather than a solution for it. Therefore, these results add to an overall argument that the construct of desire thinking should be factored in when understanding non-substance addictive behaviors like internet overuse and compulsive buying.

\section{LIMITATIONS}

Due to limited time and resources, the proposed experiment designed to investigate the relationship between shopping addiction and desire thinking was not conducted. Therefore, the results in the data section are not generated from our proposed methodology as our proposed experiment regarding binge shopping has not been validated yet. The internet-use study illustrated above was used as a reference for the expected results and hypothesis of our proposed experiment. We hypothesize that higher levels of desire thinking are positively correlated with higher levels of compulsive buying much like how higher levels of desire thinking are positively correlated with higher levels of internet addiction.

\section{DISCUSSION}

In the study conducted to investigate the relationship between desire thinking and other non-substance addictions such as internet use, it has been discovered that desire thinking may be a risk factor for these addictions, rather than a solution. Desire thinking consists of repetitive self-talk regarding the need to use the internet (in this case) and the active imagining of mental images of internet use. Therefore, it is believed that desire thinking can help reduce internet use as imaginal prefiguration and verbal perseveration would be reinforcing since they help to manage craving and negative affect by temporarily shifting attention away from these experiences and onto the elaboration of the desired target [2]. However, this would only work short term. In the medium to long-term, engagement in desire thinking would cause an increased amount of craving and negative affect as the desired target (internet use) is perseveratively elaborated upon but not achieved [2]. This, in turn, would lead to the desired target being perceived as the only, and increasingly urgent, route to attain relief from escalating distress [2]. Because of this, the addiction will only grow and continue to get worse as craving for the internet grows. Therefore, desire thinking should be conceptualized, assessed, and treated in order to reduce the risk of problematic internet use.

This reasoning behind why desire thinking may be a risk factor for other non-substance-related addictions applies to a shopping addiction in the same way. This is why the study conducted to test the relationship between desire thinking and internet use can be used as a reference for the expected results of our proposed study. If compulsive buyers attempt to use desire thinking as a solution, this may only put them at risk of buying and consuming more long-term as desire thinking only allows consumers to think about or envision buying something, increasing the craving to consume more in reality. This finding affirms the importance of discovering and analyzing the causes of our addictions and the right solutions for recovery as compulsive buying can adversely impact our wellbeing. If we find ourselves practicing desire thinking in hopes of recovering from a 
shopping addiction, we must be cautioned that this may be harmful in the long run.

These findings regarding compulsive buying also indicate that desire thinking can be utilized by marketers and retailers to increase craving and encourage those affected by compulsive buying to continue compulsively purchasing products. Compulsive shoppers who practice desire thinking would constantly desire gratification through actually purchasing something. Businesses and marketers can push and assert this consumer behavior by building commitment to their brand as consumers may find it harder to only envision the gratification from purchasing from that brand and craving for the brands' products would increase. Furthermore, businesses can build commitment through choice as people tend to feel more comfortable in a situation when given more control. Additionally, marketers may leverage desire thinking by giving people who practice it, rituals and sticking to them. Rituals might include birthday or holiday specials. People find comfort in familiar things and being without those familiar products, specials or rituals would cause consumers to crave and desire that experience of familiarity again - which can only come from purchasing from the business. However, marketers should understand that trying to exploit vulnerable consumers cannot necessarily be justified ethically. Compulsive buying has severe consequences for the individuals, as well as their family, friends, and even society [8]. In fact, considering the detrimental consequences on a person and their entire family's well-being, manufacturers and retailers are advised to instead act in a socially responsible way and help society deal with compulsive buying behavior.

These studies set the stage for future research related to the effect of desire thinking. One of which may investigate whether desire thinking can actually be a solution for a shopping addiction if interventions to buying were elaborated upon rather than the desired activity of shopping and purchasing. To test this theory, a sample group of shopping addicts can be split into three subgroups. Subgroup 1 would imagine and verbally repeat to themselves content related to saving money (their desired content) each day and subgroup 2 would desire think about content related to what they want to buy (their desired content) each day. Subgroup 3 would be given no imagine instructions (they will not practice desire thinking) in order to compare and see which way of using desire thinking would make more of a positive effect long-term. At the end of the year, it can be determined which group has the greatest will to buy more through the distribution of questionnaires and the selfreporting of participants. It is hypothesized that subgroup 1 , the group that desire thinks about saving money (the intervention to purchasing), would crave savings more and therefore have the desire to shop less compared to the other two participant groups. This is considering that past studies suggest desire thinking about desired content can lead to an increased craving for that desired content. If the hypothesis is proven to be true, it would essentially mean that desire thinking could be used to help a shopping addiction if one desired an intervention to shopping/purchasing more than he/she desired actual shopping.

Some other topics for future research may include how successful and effective current treatments for compulsive buying disorder are and how desire thinking can play into these treatments. Additionally, more research can be done on the marketing methods retail companies might use to leverage desire thinking (about shopping) displayed by consumers with a shopping addiction.

\section{CONCLUSION}

Based on the evidence identified in this review, desire to think about the desired content of purchasing products can be a risk factor for compulsive buying for those suffering from a compulsive buying disorder. However, the limited evidence available suggests that more research needs to be done in the fields of desire thinking, compulsive buying and shopping interventions. Interventions for compulsive buying currently include concentrating on saving money, detached mindfulness, cutting up credit cards, finding other meaningful ways to spend free time, and questioning beliefs about the current benefits of desire thinking.

\section{REFERENCES}

[1] Kim, H. S., \& Hodgins, D. C. (2018, August 31). Component model of addiction treatment: A pragmatic transdiagnostic treatment model of behavioral and substance addictions. Frontiers in psychiatry. Retrieved September 22, 2021, from https://www.ncbi.nlm.nih.gov/pmc/articles/PMC61 $27248 /$.

[2] Spada, M. M., Caselli, G., Slaifer, M., Nikčević, A. V., \& Sassaroli, S. (2013). Desire thinking as a predictor of problematic internet use. Social Science Computer Review, 32(4), 474-483. https://doi.org/10.1177/0894439313511318

[3] Caselli, G., \& Spada, M. M. (2011, June 27). The Desire Thinking Questionnaire: Development and psychometric properties. Addictive Behaviors. Retrieved September 23, 2021, from https://www.sciencedirect.com/science/article/pii/S 0306460311001936.

[4] Murali, V., Ray, R., \& Shaffiullha, M. (2012). Shopping addiction. Advances in Psychiatric Treatment, 18(4), 263-269. https://doi.org/10.1192/apt.bp.109.007880 
[5] Horváth, C., \& Adigüzel, F. (2018). Shopping enjoyment to the extreme: Hedonic shopping motivations and compulsive buying in developed and emerging markets. Journal of Business Research, 86, 300-310. https://doi.org/10.1016/j.jbusres.2017.07.013

[6] Andreassen, C. S., Griffiths, M. D., Pallesen, S., Bilder, R. M., Torsheim, T., \& Aboujaoude, E. (1AD, January 1). The Bergen Shopping Addiction Scale: Reliability and validity of a brief screening test. Frontiers. Retrieved September 23, 2021, from https://www.frontiersin.org/articles/10.3389/fpsyg. 2015.01374/full.

[7] Singh, M. (2014, September 1). Mood, food, and obesity. Frontiers in psychology. Retrieved September 23, 2021, from https://www.ncbi.nlm.nih.gov/pmc/articles/PMC41 50387/.

[8] Shopping addiction fueled by online shopping. Addiction Center. (2021, June 16). Retrieved September 22, 2021, from https://www.addictioncenter.com/news/2020/01/sh opping-addiction-online-shopping/. 